\title{
Persistence of tungsten oxide particle/fiber mixtures in artificial human lung fluids
}

\author{
Aleksandr B Stefaniak
}

\begin{abstract}
Background: During the manufacture of tungsten metal for non-sag wire, tungsten oxide powders are produced as intermediates and can be in the form of tungsten trioxide $\left(\mathrm{WO}_{3}\right)$ or tungsten blue oxides (TBOs). TBOs contain fiber-shaped tungsten sub-oxide particles of respirable or thoracic size. The aim of this research was to investigate whether fiber-containing TBOs had prolonged biodurability in artificial lung fluids compared to tungsten metal or $\mathrm{WO}_{3}$ and therefore potentially could pose a greater inhalation hazard.

Methods: Dissolution of tungsten metal, $\mathrm{WO}_{3}$, one fiber-free $\mathrm{TBO}\left(\mathrm{WO}_{2.98}\right)$, and three fiber-containing $\mathrm{TBO}\left(\mathrm{WO}_{2.81}\right.$, $\mathrm{WO}_{2.66}$, and $\mathrm{WO}_{2.51}$ ) powders were measured for the material as-received, dispersed, and mixed with metallic cobalt. Solubility was evaluated using artificial airway epithelial lining fluid (SUF) and macrophage phagolysosomal simulant fluid (PSF).

Results: Dissolution rates of tungsten compounds were one to four orders of magnitude slower in PSF compared to SUF. The state of the fiber-containing TBOs did not influence their dissolution in either SUF or PSF. In SUF, fibercontaining $\mathrm{WO}_{2.66}$ and $\mathrm{WO}_{2.51}$ dissolved more slowly than tungsten metal or $\mathrm{WO}_{3}$. In PSF, all three fiber-containing TBOs dissolved more slowly than tungsten metal.

Conclusions: Fiber-containing TBO powders dissolved more slowly than tungsten metal and $\mathrm{WO}_{3}$ powders in SUF and more slowly than tungsten metal in PSF. Existing pulmonary toxicological information on tungsten compounds indicates potential for pulmonary irritation and possibly fibrosis. Additional research is needed to fully understand the hazard potential of TBOs.
\end{abstract}

\section{Introduction}

Tungsten is a naturally occurring element that has industrial value in the form of its metal, oxide, and salts. One estimate suggests that up to 800,000 workers may be exposed to tungsten compounds in the United States [1]. One common application of tungsten metal is nonsag wire for light bulb filaments [2]. The production of non-sag wire involves calcination of ammonium paratungstate to yield tungsten oxide powder intermediates which are subsequently reduced under controlled conditions to yield tungsten metal powder for making wire filaments. The type of tungsten oxide intermediate produced depends on the calcination conditions, including furnace atmosphere. Yellow tungsten trioxide $\left(\mathrm{WO}_{3}\right)$ is produced if sufficient air is supplied whereas tungsten blue oxides (TBOs) having varying chemical and

Correspondence: AStefaniak@cdc.gov

National Institute for Occupational Safety and Health, Centers for Disease Control and Prevention, Morgantown, WV 26505 USA physical properties are produced under non-equilibrium conditions when air is excluded. TBO is not a welldefined compound; rather, it is a blue-colored mixture of crystalline hexagonal tungsten bronzes, $\mathrm{WO}_{3}$, and various non-stoichiometric tungsten sub-oxides and an amorphous oxide [2,3].

During production of TBOs, aerosols are generated which contain tungsten sub-oxides with fiber-shaped morphology. In a Swedish tungsten refining and manufacturing facility, airborne tungsten oxide fibers had respirable size, length $(\mathrm{L}) \geq 5 \mu \mathrm{m}$, diameter $(\mathrm{D}) \leq 3 \mu \mathrm{m}$, and aspect ratio $=\mathrm{L} / \mathrm{D}(\mathrm{AR}) \geq 5: 1$; the physical diameter of most fibers was $\leq 0.3 \mu \mathrm{m}$ [4]. Both single fibers and aggregates of fibers were observed in Swedish workplace atmospheres [4-6]. In the United States, greater than 95\% of airborne tungsten-containing fibers collected during tungsten refining and manufacturing and hard metal production had thoracic size (i.e., aerodynamic diameter $\left.\left(\mathrm{D}_{\mathrm{ae}}\right) \leq 10 \mu \mathrm{m}\right)[1,7]$.
Ciomed Central

() 2010 Stefaniak; licensee BioMed Central Ltd. This is an Open Access article distributed under the terms of the Creative Commons Attribution License (http://creativecommons.org/licenses/by/2.0), which permits unrestricted use, distribution, and reproduction in any medium, provided the original work is properly cited. 
The toxicity of fibers is influenced by their dimension, durability, and dose (at the target tissue). Fiber dimensions determine the extent to which fibers are inhaled, retained, and cleared by the lung. In humans engaged in mouth breathing, deposition in the alveolar region of the lung is maximal for fibers having $\mathrm{D}_{\mathrm{ae}}$ of $2 \mu \mathrm{m}$ and AR of 3 to 20. Biopersistence is determined by the rate at which fibers are physically cleared from the lung by mechanical action (macrophage- or mucocilliarymediated) and the rate at which they are dissolved (i.e., biodurability) in lung fluids [8,9]. Fibers longer than 20 $\mu \mathrm{m}$ that deposit on the surface of conducting airways are cleared by mechanical (i.e., mucociliary) action. Because fibers longer than $20 \mu \mathrm{m}$ that deposit in the unciliated terminal bronchioles or alveoli are not cleared from their deposition site by mucociliary action and probably cannot be engulfed and cleared by a single macrophage, they will likely remain in the lung if biodurable. Engulfment by macrophages of fibers with length between 5 and $20 \mu \mathrm{m}$ may inhibit macrophage mobility in a graded fashion. Mechanical clearance of fibers shorter than $5 \mu \mathrm{m}$ by lung alveolar macrophages is probably not influenced by fiber length $[8,9]$. Fiber chemistry, in part, determines biodurability, as does the lung fluid $\mathrm{pH}[8,9]$.

Keith et al. [10], in a U.S. Agency for Toxic Substances and Disease Registry (ATSDR) literature review, has reported the health effects from inhalation of tungsten compounds which has focused almost exclusively on non-fibrous forms. In one study, rats that inhaled tungsten carbide or were intratracheally instilled with tungsten metal or $\mathrm{WO}_{3}$ developed mild pulmonary fibrosis [10]; another rat intratrachial instillation study reported that $\mathrm{WO}_{3}$ did not affect release of biomarkers linked to fibrosis [11]. Aamodt [12] exposed beagle dogs by nose-only inhalation to $\mathrm{WO}_{3}$ particles and determined that $33 \%$ of the lung-deposited dose entered the systemic circulation, either via dissolution of particles in lung fluid or translocation to the systemic circulation by alveolar macrophages. In some workers exposed to mixed dusts containing tungsten, the tungsten-containing particles that deposit in the alveolar region of the lung persist for years [13]. Workers in the cemented tungsten carbide industry can be exposed to several tungsten compounds, including the metal, carbide, and tungstenate which vary in their solubility in the body [14]. Only one study investigated tungsten oxide fibers. In this in vitro study, laboratory-prepared tungsten oxide fibers, intended to mimic TBO materials, were observed to generate free radicals which could potentially contribute to development of pulmonary fibrosis [15]. Thus, the potential for adverse health effects following inhalation of fiber-shaped tungsten oxide particles is not understood. Given the role of fiber-shaped particles in lung toxicity we investigated whether fibercontaining TBOs are more durable in artificial lung fluids than tungsten metal or $\mathrm{WO}_{3}$ and therefore potentially could pose a greater inhalation hazard.

\section{Materials and methods \\ Study overview}

The objective of this study was to evaluate whether TBO fibers had prolonged biodurability in artificial lung fluids compared to tungsten metal or $\mathrm{WO}_{3}$. Hence, the dissolution of each tungsten oxide powder was measured in the "as-received" (aggregated), "dispersed" (individual particles), and mechanically mixed (with cobalt) states using two different artificial lung fluids. Dissolution of a pure fine tungsten metal and a fine cobalt metal obtained from a hard metal producer [16] were also measured to benchmark durability of the tungsten oxides.

Fibers may induce different pathological effects for aggregated and dispersed forms of the same material. Shvedova et al. [17] reported that aggregated singlewalled carbon nanotubes (SWCNT) were associated with induction of granulomas in mouse lung (dosing by pharyngeal aspiration), but dispersed SWCNT were associated with diffuse interstitial fibrosis and alveolar wall thickening. McKernan et al. [1] detected tungstencontaining fibers in a hard metal production facility, indicating potential for exposure to these airborne fibers beyond the intermediate stages of tungsten metal production. The presence of cobalt is known to enhance the toxicity of tungsten carbide by generating larger amounts of free radicals than equivalent masses of cobalt or tungsten carbide alone [18]. Thus, we measured dissolution for each aggregated powder mixed with cobalt at a ratio of 95:5 by weight. These admixtures do not represent any specific industrial powder formulations but were created to understand the codissolution of tungsten in the presence of cobalt.

\section{Study powders}

Five bulk tungsten oxide powders were provided for study by an industrial producer of non-sag tungsten metal wire: yellow $\mathrm{WO}_{3}$ and the TBOs $\mathrm{WO}_{2.98}, \mathrm{WO}_{2.81}$, $\mathrm{WO}_{2.66}$, and $\mathrm{WO}_{2.51}$. The only defined tungsten oxide is $\mathrm{WO}_{3}$; the TBOs were manufactured under non-equilibrium conditions and the oxidative states of these powders are average values. The $\mathrm{WO}_{2.98}$ is crystallographically $\mathrm{WO}_{3}$, but has oxygen defects that impart a blue-color to the material. $\mathrm{WO}_{2.81}$ is a mixture of $\mathrm{WO}_{2.90}$ and $\mathrm{WO}_{2.72}$, whereas both $\mathrm{WO}_{2.66}$ and $\mathrm{WO}_{2.51}$ are mixtures of varying proportions of $\mathrm{WO}_{2.72}$ and $\mathrm{WO}_{2}$. The $\mathrm{WO}_{3}$ and $\mathrm{WO}_{2.98}$ powders were examined microscopically as described below and consisted of isometric-shaped particles and accounted for approximately 
$80 \%$ of this manufacturer's production. The $\mathrm{WO}_{2.81}$, $\mathrm{WO}_{2.66}$, and $\mathrm{WO}_{2.51}$ powders were examined microscopically and were mixtures of isometric and fiber particle morphologies and accounted for the remaining $20 \%$ of industrial production.

\section{Study powder characterization}

A field emission scanning electron microscope (SEM; model S-4800, Hitachi, Tokyo, Japan) was used to evaluate morphology, aggregation state, and external dimensions of the as received and dispersed powders (see Figure 1). Powders were dispersed using distilled water and deposited onto a $0.025 \mu \mathrm{m}$ pore-size nitrocellulose filter [19]. Helium pycnometry was used to determine powder density by gas displacement (AccuPyc II 1340 Analyzer, Micromeritics, Norcross, GA). Nitrogen gas adsorption was used to determine powder specific surface area (SSA) using a multipoint Brunauer, Emmett, and Teller (BET) instrument (Quadrasorb surface area analyzer, Quantachrome, Boynton Beach, FL). Prior to analysis, powders were outgassed under vacuum $(0.013$ torr) at $200^{\circ} \mathrm{C}$ overnight to remove moisture [20].

The U.S. National Institute for Occupational Safety and Health (NIOSH) Method 7400 with "B" counting rules was used to count tungsten-containing fibers, i.e., $\mathrm{L}>5 \mu \mathrm{m}, \mathrm{D}<3 \mu \mathrm{m}$, and AR of $\geq 5: 1[1,7]$. The relative mass fractions of isometric- and fiber-shaped particles in each powder was calculated from measures of 150 to 300 particle external dimensions in 27 to 50 microscope fields per material and the measured density. The orientation-averaged fiber $\mathrm{D}_{\mathrm{ae}}$ was calculated as described by Griffiths and Vaughn [21]. For isometric-shaped particles, $\mathrm{D}_{\mathrm{ae}}$ was calculated assuming a dynamic shape factor $(\chi)$ of 1.08 for cube-shaped $\mathrm{WO}_{3}$ and $\mathrm{WO}_{2.98}$ particles and $\chi$ of 1.00 for spherical tungsten and cobalt particles [22].

Total $\mathrm{C}, \mathrm{H}$, and $\mathrm{N}$ impurity content $[23,24]$ and $\mathrm{S}$ impurity content [25] of powders were determined by combustion by a commercial laboratory (Galbraith Laboratories, Knoxville, TN). Oxygen content was assayed by pyrolysis (LECO Corp, St. Joseph, MI). Inductively coupled plasma (ICP)-atomic emission spectroscopy was used to quantify metal impurities in accordance with NIOSH Method 7303: Elements by ICP [26]. $\mathrm{X}$-ray photoelectron spectroscopy was used to evaluate powder surface (top $20 \AA$ ) chemistry (McCrone Associates, Westmont, IL).

\section{Artificial Lung Fluid Dissolution Studies}

Dissolution of triplicate samples of each powder was evaluated using a static technique [27]. Known masses (in the range 10 to $100 \mathrm{mg}$ ) of each study powder were determined gravimetrically using a calibrated five-place balance (Model AX 205, Mettler Toledo, Greifensee,

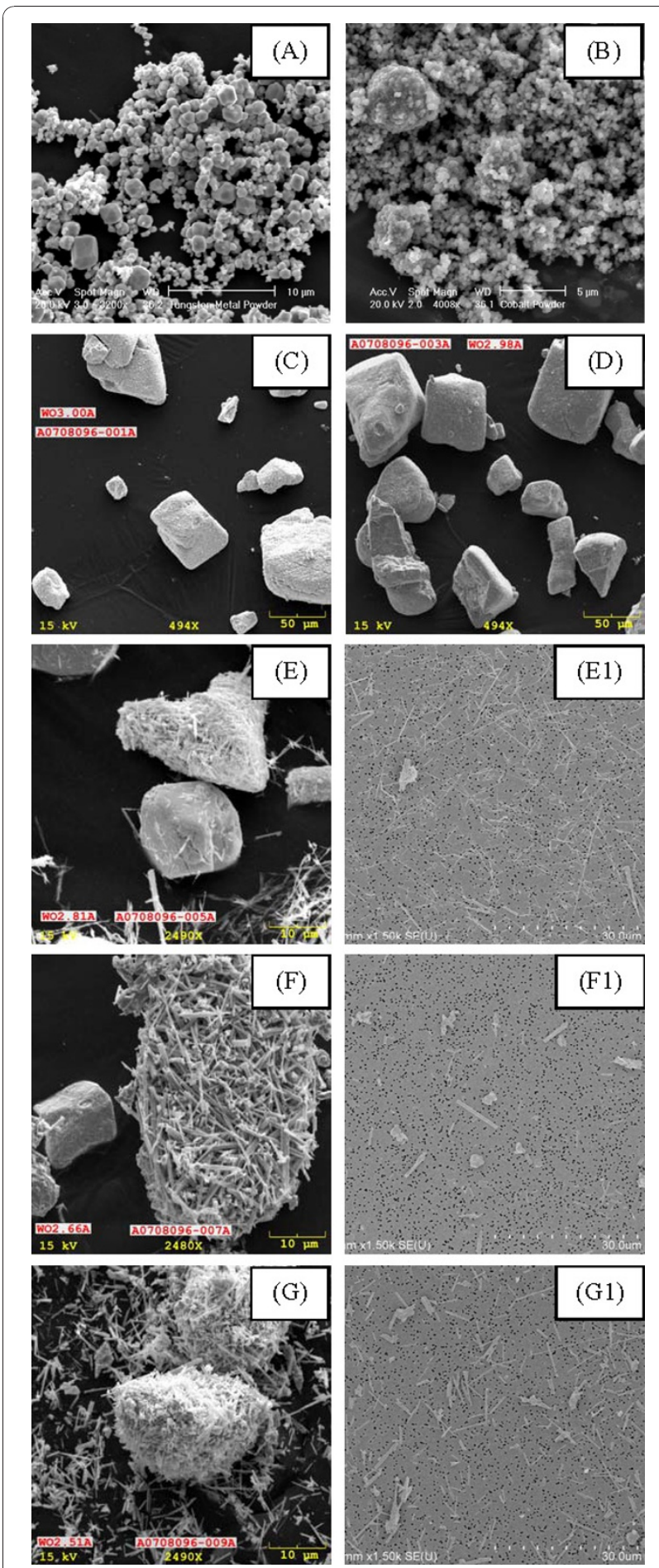

Figure 1 Scanning electron micrographs of study powders: "as-received" (A) W metal, (B) Co metal, (C) $\mathrm{WO}_{3}$, (D) $\mathrm{WO}_{2.98}$, (E) $\mathrm{WO}_{2.81},(\mathrm{~F}) \mathrm{WO}_{2.66}$, and (G) $\mathrm{WO}_{2.51}$ powders. The $\mathrm{W}$ and $\mathrm{Co}$ powders were agglomerates of primary particles, the $\mathrm{WO}_{3}$ and $\mathrm{WO}_{2.98}$ powders were cube-shaped isometric particle morphology, and the $\mathrm{WO}_{2.81}, \mathrm{WO}_{2.66}$, and $\mathrm{WO}_{2.51}$ powders were mixtures of fiberand cube-shaped particle morphologies; "dispersed" (E1) WO $\mathrm{WO}_{2.81}$, (F1) $W_{2.66}$, and (G1) $W_{2.51}$ powders illustrating individual fiber morphology. Note that the scale bars differ among images. 
Switzerland) capable of reading to $10 \mu \mathrm{g}$. Each static dissolution chamber was placed in a separate polypropylene cup, immersed in $80 \mathrm{~mL}$ of artificial lung fluid, covered with a lid having two holes to allow gas exchange, and maintained at $37{ }^{\circ} \mathrm{C}$ throughout an experiment.

Serum ultrafiltrate (SUF) was used to model dissolution in lung airway epithelial lining fluid [28]. This solvent consists of chloride (217.5 mM), sodium (145.7 $\mathrm{mM})$, ammonium $(100.0 \mathrm{mM})$, calcium $(29.4 \mathrm{mM})$, bicarbonate $(27.0 \mathrm{mM})$, cysteine $(1.1 \mathrm{mM})$, phosphate $(1.0 \mathrm{mM})$. sulfate $(0.6 \mathrm{mM})$, citrate $(0.2 \mathrm{mM})$, and diethylenetriaminepentaacetic acid $(2 \mathrm{mM})$, the latter to prevent formation of insoluble phosphate precipitates. The $\mathrm{pH}$ of SUF was maintained at $7.4 \pm 0.1$ by blanketing the headspace in each sample with $5 \% \mathrm{CO}_{2}$ and $95 \%$ air. Masses of dissolved tungsten were measured after 1 , $3,6,12,24,36,48$, and 72 hours to mimic the residence time of particles in extracellular lung fluid [29]. Phagolysosomal simulant fluid (PSF) buffered with $0.02 \mathrm{M}$ potassium hydrogen phthalate was used to model dissolution in lung alveolar macrophages [30]. This solvent consists of sodium (116.8 mM), chloride (114.2 mM), potassium $(25.0 \mathrm{mM})$, glycine $(6.0 \mathrm{mM})$, phosphate $(1.0$ $\mathrm{mM})$, sulfate $(0.5 \mathrm{mM})$, and calcium $(0.2 \mathrm{mM})$. The $\mathrm{pH}$ of PSF remained at $4.5 \pm 0.1$ throughout experiments. Masses of dissolved tungsten were measured at 1, 4, 8, 12,24 , and 72 hours, and then twice weekly thereafter to 31 days to mimic the approximate lifespan of an alveolar macrophage [31]. In pilot studies, alkylbenzyldimethylammonium chloride, added to artificial lung fluids to prevent mold growth, inhibited dissolution of some tungsten oxide powders and was omitted from the full-scale experiments. Rather, mold growth was prevented by using sterile labware and laboratory practices.

Experimental and quality control samples were analyzed using U.S. Occupational Safety and Health Administration Method 213: Tungsten and Cobalt in Workplace Atmospheres: inductively coupled plasma analysis [32]. Analysis of dissolved tungsten was performed using inductively coupled plasma-atomic emission spectroscopy (ICP-AES) without sample digestion. The analytical limit of detection (LOD) for tungsten in SUF was $0.03 \mathrm{mg} \mathrm{L}^{-1}$ and the limit of quantification (LOQ) was $0.11 \mathrm{mg} \mathrm{L}^{-1}$. For PSF, the tungsten LOD was $0.08 \mu \mathrm{g} \mathrm{L}^{-1}$ and the LOQ was $0.27 \mu \mathrm{g} \mathrm{L}^{-1}$. Undissolved particulate in the dissolution chambers exposed to SUF and PSF were digested and masses of tungsten quantified using ICP-AES; the tungsten LOD was $0.1 \mu \mathrm{g}$ sam$\mathrm{ple}^{-1}$ and the LOQ was $0.43 \mu \mathrm{g}$ sample ${ }^{-1}$.

\section{Data analyses}

Dissolution parameters for isometric-shaped powders $\left(\mathrm{W}, \mathrm{WO}_{3}\right.$ and $\left.\mathrm{WO}_{2.98}\right)$ were calculated using a surface- area-limited dissolution model [33]. Dissolution parameters for fiber-containing powders $\left(\mathrm{WO}_{2.81}, \mathrm{WO}_{2.66}\right.$, and $\mathrm{WO}_{2.51}$ ) were calculated assuming constant dissolution velocity [34]:

$$
1-\left(\frac{M}{M_{0}}\right)^{\frac{1}{2}}=\frac{2 k t}{d_{0} \rho} .
$$

where $\frac{M}{M_{0}}$ is the mass fraction of material remaining, $t$ is time (days), $d_{0}$ is the average initial fiber diameter $(\mu \mathrm{m})$ from SEM analysis, $\rho$ is the measured fiber density $\left(\mathrm{g} / \mathrm{cm}^{3}\right)$, and $k$ is the chemical dissolution rate constant $\left[\mathrm{g} /\left(\mathrm{cm}^{2} \cdot\right.\right.$ day $\left.)\right]$. Values of $1-\left(\frac{M}{M_{0}}\right)^{\frac{1}{2}}$ were plotted versus time and non-linear least squares regression models used to estimate the best fit line for the data. The slope value, $b$, for this line was used to calculate $t_{1 / 2}$ (i.e., $-0.693 / \mathrm{b}$ ) and to estimate $k$ (i.e., b/SSA).

For $\mathrm{WO}_{2.81}$ and $\mathrm{WO}_{2.51}$ in PSF, dissolution data were best described by two negative exponentials, i.e., both a shorter term and a longer term dissolution behavior (see Figure 2B). For these specific cases, a two-part segmented regression model was used to determine the point at which the shorter term phase ended and the longer term phase began [35].

Values of ${ }_{1-}\left(\frac{M}{M_{0}}\right)^{\frac{1}{2}}$ were plotted versus time; however, only the linear portion of the segmented regression, which corresponded to the longer-term dissolution phase was used to calculate dissolution parameters. The slope of the best fit line from the plotted data, b, was used to calculate $t_{1 / 2}$ and $k$ as noted above.

Analysis of variance F-statistics were used to identify overall differences in dissolution half-times and mean rate constants among materials. Tukey's test was used to identify differences between paired means.

\section{Results}

Figure 1 illustrates the morphology of the tungsten oxide study powders. The $\mathrm{W}$ and Co powders were both clusters of spherical primary particles. In the as-received state, the $\mathrm{WO}_{3}$ and $\mathrm{WO}_{2.98}$ powders were large, compact, mostly cube-shaped particles. The $\mathrm{WO}_{2.81}, \mathrm{WO}_{2.66}$, and $\mathrm{WO}_{2.51}$ powders were mixtures of compact cubeshaped and fiber-shaped particles. Dispersed $\mathrm{WO}_{2.81}$ and $\mathrm{WO}_{2.51}$ both contained long, thin fibers and cubeshaped particles, whereas $\mathrm{WO}_{2.66}$ contained short, cylinder-shaped and cube-shaped particles.

Table 1 summarizes the physical properties of the study powders. Measured density values for the well-defined $\mathrm{WO}_{3.00}$ and $\mathrm{W}$ were near theoretical values. The measured density value for Co was slightly lower than 

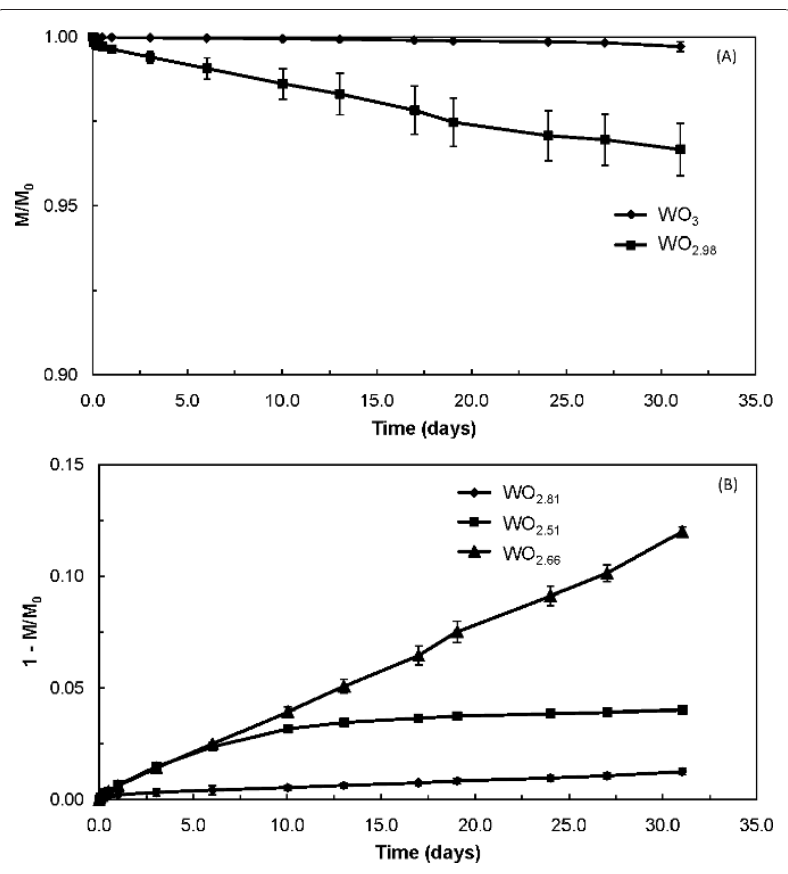

Figure 2 Plots of tungsten oxide powder dissolution for the as-received state in phagolysosomal simulant fluid.

(A) isometric-shaped $\mathrm{WO}_{3}$ and $\mathrm{WO}_{2.98}$ powders illustrating singlephase dissolution that was best described by a single negative exponential. Dissolution parameters were calculated using a surface-area-limited dissolution model [33]. Note that the $y$-axis scale is mass fraction remaining $\left(M / M_{0}\right)$ and plotted values from 0.90 to 1.0 to illustrate the shape of the curves. (B) fibercontaining $\mathrm{WO}_{2.81}, \mathrm{WO}_{2.66}$, and $\mathrm{WO}_{2.51}$ powders; $\mathrm{WO}_{2.81}$ and $\mathrm{WO}_{2.51}$ illustrate biphasic dissolution that was described by two negative exponentials (the first for the initial rapid dissolution phase and the second for the latter long-term phase) whereas WO2.66 was best described by a single negative exponential. Dissolution parameters for the fiber-containing materials were calculated using a constant dissolution velocity model [34]. Note that the $y$-axis is $1-\left(\mathrm{M} / \mathrm{M}_{0}\right)$ and plotted values range from 0.0 to 0.15 to illustrate the shapes of the curves; hence, the fraction of material dissolved during the initial phase was low, usually less than $2 \%$ of the total. theoretical due to the presence of less dense cobalt oxide on particle surfaces as previously determined using Auger spectroscopy [36]. For the TBO powders, density generally increased as powder oxygen content (density $1.3 \mathrm{~g} / \mathrm{cm}^{3}$ ) decreased relative to the tungsten content (density $19.2 \mathrm{~g} / \mathrm{cm}^{3}$ ) per unit volume of powder. SSA, which depends on particle diameter, density, and surface characteristics (roughness, pores, etc), varied by up to a factor of 15 among powders. Among the $\mathrm{WO}_{2.81}$, $\mathrm{WO}_{2.66}$, and $\mathrm{WO}_{2.51}$ powders, geometric mean (GM) physical fiber lengths were 6 to $8 \mu \mathrm{m}$ and diameters were $\leq 0.5 \mu \mathrm{m}$. The $\mathrm{WO}_{2.81}$ and $\mathrm{WO}_{2.51}$ powders were $80 \%$ fibers by mass. In contrast, for $\mathrm{WO}_{2.66}$ powder, many particles were cylinder-shaped, but only $38 \%$ met the definition for a fiber using NIOSH B counting rules.

Tungsten oxide powder surfaces were composed of tungsten and oxygen with minor amounts of carbon, which is consistent with tungsten oxides. Measured oxygen content of the well-defined $\mathrm{WO}_{3}$ material was greater than $95 \%$ of that predicted from the formula weight. The measured oxygen contents of the $\mathrm{WO}_{2.98}$, $\mathrm{WO}_{2.81}, \mathrm{WO}_{2.66}$, and $\mathrm{WO}_{2.51}$ powders were $19 \pm 3 \%, 19$ $\pm 0 \%, 16 \pm 1 \%$, and $16 \pm 4 \%$, respectively, which are consistent with the masses expected from the average stoichiometries of the powder constituents. The oxygen content of the tungsten metal study powder was $<0.3 \%$. Levels of impurities in the tungsten oxide materials were either below analytical LODs or $\leq 0.001 \%$ by weight $(\mathrm{Sb}, \mathrm{Ba}, \mathrm{Cr}, \mathrm{Cu}, \mathrm{Fe}, \mathrm{Se}$, and $\mathrm{V}$ ).

\section{Dissolution results}

In general, tungsten dissolution from each study powder consisted of a single phase that was best described by a single negative exponential. For a few powder/solvent combinations, dissolution was biphasic, consisting of an initial rapid dissolution phase followed by a long-term dissolution phase; these data were best described by two negative exponentials. The fraction of material dissolved

Table 1 Physical properties of study powders

\begin{tabular}{|c|c|c|c|c|c|c|c|c|c|c|c|}
\hline \multirow[b]{2}{*}{ Powder } & \multirow[b]{2}{*}{ Density $\left(\mathrm{g} / \mathrm{cm}^{3}\right)$} & \multirow[b]{2}{*}{$\mathrm{SSA}\left(\mathrm{m}^{2} / \mathrm{g}\right)$} & \multicolumn{2}{|c|}{$D_{\text {phys }}(\mu \mathrm{m})^{\mathrm{a}}$} & \multicolumn{2}{|c|}{$\mathrm{L}_{\text {phys }}(\mu \mathrm{m})$} & \multirow{2}{*}{$\frac{\mathrm{L}_{\text {phys }} / \mathrm{D}_{\text {phys }}}{\mathrm{GM}}$} & \multicolumn{2}{|c|}{$D_{a e}(\mu m)$} & \multicolumn{2}{|c|}{ Mass $(\%)^{b}$} \\
\hline & & & $A M \pm S D$ & GM (GSD) & $A M \pm S D$ & GM (GSD) & & $A M \pm S D$ & GM (GSD) & 1 & $F$ \\
\hline $\mathrm{WO}_{3}$ & $7.2 \pm 0.0$ & $0.75 \pm 0.03$ & $36.2 \pm 20.4$ & $31.1(1.8)$ & $-^{c}$ & - & - & $94 \pm 53$ & $80.4(1.8)$ & 100 & 0 \\
\hline $\mathrm{WO}_{2.98}$ & $7.0 \pm 0.0$ & $11.10 \pm 0.76$ & $37.5 \pm 26.0$ & $29.8(2.0)$ & - & - & - & $95 \pm 66$ & $75.8(2.0)$ & 100 & 0 \\
\hline$W_{2.81}$ & $7.1 \pm 0.0$ & $2.85 \pm 0.02$ & $0.3 \pm 0.3$ & $0.2(2.0)$ & $8.8 \pm 5.6$ & $7.8(1.6)$ & 38 & $1.7 \pm 1.4$ & $1.4(1.8)$ & 21 & 79 \\
\hline $\mathrm{WO}_{2.66}$ & $8.2 \pm 0.0$ & $1.50 \pm 0.07$ & $0.5 \pm 0.1$ & $0.5(1.1)$ & $6.3 \pm 0.7$ & $6.3(1.1)$ & 12 & $3.1 \pm 0.3$ & $3.1(1.1)$ & 62 & 38 \\
\hline $\mathrm{WO}_{2.51}$ & $7.7 \pm 0.1$ & $2.10 \pm 0.02$ & $0.5 \pm 0.2$ & $0.5(1.5)$ & $7.6 \pm 3.0$ & $7.2(1.4)$ & 15 & $3.0 \pm 0.9$ & $2.9(1.4)$ & 21 & 79 \\
\hline W & $19.2 \pm 0.1$ & $0.68 \pm 0.09$ & $2.5 \pm 1.9$ & $2.0(2.0)$ & - & - & - & $11.1 \pm 8.1$ & $8.8(2.0)$ & 100 & 0 \\
\hline $\mathrm{Co}$ & $8.2 \pm 0.1$ & $7.30 \pm 0.24$ & $2.4 \pm 1.7$ & $1.9(1.9)$ & - & - & - & $6.8 \pm 4.9$ & $5.5(1.9)$ & 100 & 0 \\
\hline
\end{tabular}

${ }^{a} D_{\text {phys }}=$ physical diameter; $L_{\text {phys }}=$ physical length; $D_{a e}=$ aerodynamic diameter. $D_{a e}$ values in the Table are orientation-averaged values for the fiber-shaped fractions of the $W_{2.81}, W_{2.66}$, and $W_{2.51}$ powders). Calculated $D_{\text {ae }}$ values for the isometric-shaped particle fraction of the $W_{2.81}, W_{2.66}$, and $W_{2.51}$ powders are $2.5 \pm 1.5,7.5 \pm 6.0$, and $3.7 \pm 1.8 \mu \mathrm{m}$, respectively.

b Particles having isometric (I)- or fiber (F)-shaped morphology.

c - Not applicable for materials of isometric morphology only. 
during the initial phase was low, usually less than $2 \%$ of the total, so reported dissolution rates refer only to the long-term phase (see Figure 2).

\section{Artificial airway epithelial lining fluid}

Table 2 summarizes the fitted long-term dissolution parameters for the tungsten oxide powders in three states (as-received, dispersed, and mixed with cobalt) for a 72-hour immersion in SUF. In the as-received state, values of $t_{1 / 2}$ for the fiber-containing $\mathrm{WO}_{2.51}$ and $\mathrm{WO}_{2.66}$ powders were longer and their corresponding $k$ values were slower compared to all other powders ( $\mathrm{p}$ $<0.05)$. In the dispersed state, values of $t_{1 / 2}$ for the fiber-containing $\mathrm{WO}_{2.51}$ and $\mathrm{WO}_{2.66}$ powders were longer than for the other tungsten oxide powders $(\mathrm{p}<$ 0.05). Dispersed fiber-containing $\mathrm{WO}_{2.81}, \mathrm{WO}_{2.66}$, and $\mathrm{WO}_{2.51}$ powders had slower $k$ values than the isometric-shaped $\mathrm{WO}_{3}$ and $\mathrm{WO}_{2.98}$ powders $(\mathrm{p}<0.05)$. Dissolution of cobalt in SUF was biphasic and independent of the presence of any tungsten oxide powder (data not shown). The dissolution half-time for $\mathrm{WO}_{2.98}$ was shortest among all tungsten oxide/cobalt powder mixtures $(\mathrm{p}<0.05)$. There were no differences in $k$ values among the tungsten oxide powders mixed with cobalt.

For a given fiber-containing tungsten oxide powder, $k$ values in SUF did not differ among the as-received, dispersed, and mixture states. Dissolution rates ( $k$-values) for the isometric-shaped $\mathrm{WO}_{3}$ and $\mathrm{WO}_{2.98}$ powders did not differ between the as-received and dispersed states; however, in the presence of cobalt their rates were slower.

\section{Artificial alveolar macrophage phagolysosomal fluid}

Table 3 summarizes the fitted long-term dissolution parameters for the tungsten-containing powders during 31 days of immersion in PSF. In general, dissolution rates of tungsten oxides in PSF were one to four orders of magnitude slower than in SUF. In the as-received state, $\mathrm{t}_{1 / 2}$ ranged from 97 days $(\mathrm{W})$ to 9893 days $\left(\mathrm{WO}_{3}\right)$ with the rank order (from longest to shortest) being:
$\mathrm{WO}_{3} \approx \mathrm{WO}_{2.98} \approx \mathrm{WO}_{2.81} \approx \mathrm{WO}_{2.51}>\mathrm{WO}_{2.66}>\mathrm{W}(\mathrm{p}<$ 0.05 ). The corresponding rank order of $k$ values (from fastest to slowest) was: $\mathrm{W}>\mathrm{WO}_{2.66}>\mathrm{WO}_{3} \approx \mathrm{WO}_{2.98} \approx$ $\mathrm{WO}_{2.81} \approx \mathrm{WO}_{2.51}(\mathrm{p}<0.05)$. In the as-received state, the $k$ value for $\mathrm{W}$ metal was faster than that for $\mathrm{WO}_{2.66}$ and the rates for these two compounds were both faster than the rates for the remaining tungsten oxides ( $\mathrm{p}<$ $0.05)$. In the dispersed state, $t_{1 / 2}$ values ranged from hundreds to thousands of days; $\mathrm{WO}_{2.66}$ was significantly faster than all other oxide powders. The dissolution rate for dispersed fiber-containing $\mathrm{WO}_{2.66}$ powder was faster than rates for all other dispersed tungsten oxide powders $(\mathrm{p}<0.05)$. There was no difference in $k$ values among the dispersed $\mathrm{WO}_{3}, \mathrm{WO}_{2.98}, \mathrm{WO}_{2.81}$, and $\mathrm{WO}_{2.51}$ powders. In the powder mixtures, dissolution of cobalt was independent of tungsten oxide (data not shown). When mixed with cobalt, $t_{1 / 2}$ values for the tungsten oxide powders ranged from 200 to 8000 days; $\mathrm{WO}_{2.66}$ was significantly faster than all other oxide powders. The corresponding $k$-value for $\mathrm{WO}_{2.66}$ powder was faster than all other tungsten oxide powders $(\mathrm{p}<0.05)$.

For a given tungsten oxide powder, values of $t_{1 / 2}$ did not differ among states in PSF with the exception of a longer half-time for $\mathrm{WO}_{3}$ in the dispersed state than in the as-received and mixed states. For a given powder, its $k$-values did not differ among states in PSF.

\section{Discussion}

The rate at which materials are cleared from the respiratory tract depends upon the location in which the material deposits, the physicochemical form of the material, and the time since deposition [37]. In the present study, dissolution was evaluated for tungsten oxides having varying physicochemical properties in two artificial lung environments, one mimicking the fluid lining the airways (i.e., SUF) and the other mimicking the fluid contained in alveolar macrophage phagolysosomes (i.e., PSF). Clear differences in dissolution behavior were observed among and within tungsten oxide powders in

Table 2 Long-term dissolution parameters (mean \pm standard deviation) for tungsten-containing materials after immersion in artificial airway epithelial lining fluid (pH 7.4) for 72 hours

\begin{tabular}{|c|c|c|c|c|c|c|}
\hline \multirow[b]{2}{*}{ Powder } & \multicolumn{2}{|c|}{ As Received } & \multicolumn{2}{|c|}{ Dispersed } & \multicolumn{2}{|c|}{ Mixture with Cobalt } \\
\hline & $\mathrm{t}_{1 / 2}$ (days) & $k\left[\mathrm{~g} /\left(\mathrm{cm}^{2} \cdot\right.\right.$ day $\left.)\right]$ & $t_{1 / 2}$ (days) & $k\left[\mathrm{~g} /\left(\mathrm{cm}^{2}\right.\right.$ day $\left.)\right]$ & $t_{1 / 2}$ (days) & $k\left[\mathrm{~g} /\left(\mathrm{cm}^{2} \cdot\right.\right.$ day $\left.)\right]$ \\
\hline $\mathrm{WO}_{3}$ & $4 \pm 1$ & $2.5 \pm 0.3 \times 10^{-5}$ & $11^{a}$ & $0.9 \times 10^{-5}$ & $79 \pm 23$ & $1.3 \pm 0.4 \times 10^{-6}$ \\
\hline $\mathrm{WO}_{2.98}$ & $1 \pm 0$ & $6.0 \pm 1.2 \times 10^{-6}$ & $1 \pm 0$ & $6.0 \pm 2.3 \times 10^{-6}$ & $10 \pm 2$ & $6.5 \pm 1.6 \times 10^{-7}$ \\
\hline $\mathrm{WO}_{2.81}$ & $11 \pm 2$ & $2.3 \pm 0.3 \times 10^{-6}$ & $13 \pm 1$ & $1.9 \pm 0.1 \times 10^{-6}$ & $71 \pm 6$ & $3.5 \pm 0.3 \times 10^{-7}$ \\
\hline $\mathrm{WO}_{2.66^{\mathrm{b}}}$ & $56 \pm 10$ & $8.4 \pm 1.7 \times 10^{-7}$ & $41 \pm 2$ & $1.1 \pm 0.1 \times 10^{-6}$ & $72 \pm 22$ & $6.8 \pm 1.8 \times 10^{-7}$ \\
\hline $\mathrm{WO}_{2.51}$ & $81 \pm 4$ & $4.1 \pm 0.2 \times 10^{-7}$ & $50 \pm 14$ & $6.9 \pm 1.7 \times 10^{-7}$ & $89 \pm 13$ & $3.8 \pm 0.6 \times 10^{-7}$ \\
\hline W & $19 \pm 2$ & $5.4 \pm 0.5 \times 10^{-6}$ & $-^{c}$ & - & - & - \\
\hline
\end{tabular}

${ }^{a}$ Result for $\mathrm{WO}_{3}$ in dispersed state is for $\mathrm{n}=1$ sample.

${ }^{\mathrm{b}}$ Values for $\mathrm{t}_{1 / 2}$ (days) and $k\left[\mathrm{~g} /\left(\mathrm{cm}^{2}\right.\right.$.day) $]$ calculated using surface-area-limited dissolution model: $30 \pm 6,1.6 \pm 0.3 \times 10^{-6}$ (as-received); $22 \pm 2,2.1 \pm 0.2 \times 10^{-6}$ (dispersed); $37 \pm 11,1.3 \pm 0.3 \times 10^{-6}$ (mixture).

c Not applicable for the tungsten metal samples. 
Table 3 Long-term dissolution parameters (mean \pm standard deviation) for tungsten-containing materials after immersion in artificial lung alveolar macrophage phagolysosomal fluid (pH 4.5) for 31 days

\begin{tabular}{|c|c|c|c|c|c|c|}
\hline \multirow[b]{2}{*}{ Powder } & \multicolumn{2}{|c|}{ As Received } & \multicolumn{2}{|c|}{ Dispersed } & \multicolumn{2}{|c|}{ Mixture with Cobalt } \\
\hline & $t_{1 / 2}$ (days) & $k\left[\mathrm{~g} /\left(\mathrm{cm}^{2} \cdot\right.\right.$ day $\left.)\right]$ & $t_{1 / 2}$ (days) & $k\left[\mathrm{~g} /\left(\mathrm{cm}^{2} \cdot\right.\right.$ day $\left.)\right]$ & $t_{1 / 2}$ (days) & $k\left[\mathrm{~g} /\left(\mathrm{cm}^{2} \cdot\right.\right.$ day $\left.)\right]$ \\
\hline$\overline{\mathrm{WO}_{3}}$ & $9893 \pm 2549$ & $9.8 \pm 2.9 \times 10^{-9}$ & $21541 \pm 1890$ & $4.3 \pm 0.4 \times 10^{-9}$ & $8052 \pm 2458$ & $1.1 \pm 0.4 \times 10^{-8}$ \\
\hline$W_{2.98}$ & $656 \pm 154$ & $9.9 \pm 2.6 \times 10^{-9}$ & $929 \pm 45$ & $6.8 \pm 0.3 \times 10^{-9}$ & $655 \pm 72$ & $9.6 \pm 1.0 \times 10^{-9}$ \\
\hline $\mathrm{WO}_{2.81}$ & $2218 \pm 84$ & $1.1 \pm 0.0 \times 10^{-8}$ & $2207 \pm 144$ & $1.1 \pm 0.1 \times 10^{-8}$ & $2084 \pm 102$ & $1.2 \pm 0.1 \times 10^{-8}$ \\
\hline $\mathrm{WO}_{2.66^{a}}{ }^{\mathrm{a}}$ & $181 \pm 7$ & $2.6 \pm 0.1 \times 10^{-7}$ & $214 \pm 6$ & $2.2 \pm 0.1 \times 10^{-7}$ & $218 \pm 17$ & $2.1 \pm 0.2 \times 10^{-7}$ \\
\hline$W_{2.51}$ & $2455 \pm 422$ & $1.4 \pm 0.2 \times 10^{-8}$ & $2915 \pm 414$ & $1.1 \pm 0.2 \times 10^{-8}$ & $1343 \pm 252$ & $2.5 \pm 0.5 \times 10^{-8}$ \\
\hline W & $97 \pm 17$ & $1.1 \pm 0.2 \times 10^{-6}$ & $-^{\mathrm{b}}$ & - & - & - \\
\hline
\end{tabular}

${ }^{a}$ Values for $t_{1 / 2}$ (days) and $k\left[\mathrm{~g} /\left(\mathrm{cm}^{2} \cdot\right.\right.$ day)] calculated using surface-area-limited dissolution model: $87 \pm 4,5.3 \pm 0.2 \times 10^{-7}$ (as-received); $106 \pm 3,4.4 \pm 0.1 \times 10^{-7}$ (dispersed); $101 \pm 8,4.6 \pm 0.4 \times 10^{-7}$ (mixture).

${ }^{\mathrm{b}}$ Not applicable for the tungsten metal samples

SUF and PSF. Such differences are important for understanding the relative persistence of tungsten oxides in the lung.

Mechanical clearance half-times for durable particles that deposit in the conducting airways are approximately 8 hours (bronchioles to bronchi), 100 minutes (bronchi to extrathoracic airways), and 10 minutes (extrathoracic airways to the gastrointestinal tract) via the mucociliary escalator [37]. In SUF, the as-received and dispersed $\mathrm{WO}_{3}$ and $\mathrm{WO}_{2.98}$ had the fastest dissolution rates among all the studied powders, though the presence of cobalt slowed dissolution of these materials. Based on the measured surface area and dissolution rates, the amounts of material dissolved from $\mathrm{WO}_{3}$ in each of the above-listed clearance half-times would be $6 \%$ ( 8 hours), $1 \%$ (100 minutes), and $0.1 \%$ (10 minutes), whereas the amounts of material dissolved from $\mathrm{WO}_{2.98}$ would be $20 \%$ (8 hours), $5 \%$ (100 minutes), and $0.5 \%$ (10 minutes). Thus, clearance of these materials from the conducting airways would include both mechanical action and dissolution. The $\mathrm{WO}_{3}$ and $\mathrm{WO}_{2.98}$ powders are crystallographically similar materials and the high solubility of these materials supports the results of Aamodt [12], who observed that approximately one-third of an inhaled $\mathrm{WO}_{3}$ particle dose enters systemic circulation. Interestingly, in all states evaluated, $\mathrm{WO}_{2.66}$ dissolved faster in SUF than the other fiber-containing samples which may be due to its higher mass fraction of isometric-shaped particles (Table 1). However, in all states evaluated, the fiber-containing tungsten oxide powders dissolved more slowly than the isometric-shaped materials. This suggests that clearance of fiber-containing tungsten oxide powders from the conducting airways would be dominated by mechanical mechanisms with little $(<1 \%)$ dissolving during a single clearance halftime.

The orientation-averaged $\mathrm{D}_{\mathrm{ae}}$ and aspect ratios of the $\mathrm{WO}_{2.81}, \mathrm{WO}_{2.66}$, and $\mathrm{WO}_{2.51}$ fibers indicate that they were respirable, with high probability of deposition in the non-ciliated alveolar region of the lung
(Table 1). The dimensions of fibers in these bulk tungsten oxide powders are consistent with previous reports that airborne tungsten oxide fibers in workplace atmospheres had respirable or thoracic size $[1,4,7]$. Within 24 hours, $90 \%$ of particles deposited in the alveolar region of the lung are associated with macrophage cells [29]. The lengths of the $\mathrm{WO}_{2.81}$, $\mathrm{WO}_{2.66}$, and $\mathrm{WO}_{2.51}$ fibers ranged from 6 to $9 \mu \mathrm{m}$, which is sufficient to inhibit their clearance from alveoli by macrophages $[8,9]$. As such, dissolution in macrophage phagolysosomal fluid is likely to play an important role in the clearance of relatively insoluble materials such as TBO fibers that deposit in the alveolar region of the lung.

Often, rate of metal dissolution increases as solvent $\mathrm{pH}$ decreases [38]. However, in the current study, dissolution rates of each tungsten oxide material were up to four orders of magnitude slower in PSF than in SUF, indicating potential for long-term retention of tungsten oxides that deposit in the alveolar region of the lung. With regards to dissolution in PSF, the fiber-containing $\mathrm{WO}_{2.81}, \mathrm{WO}_{2.66}$, and $\mathrm{WO}_{2.51}$ powders dissolved more slowly in the as-received state than tungsten metal powder, indicating potential for longer persistence in the alveoli. In the dispersed and mixed states, $\mathrm{WO}_{2.66}$ powder, but not $\mathrm{WO}_{2.81}$ or $\mathrm{WO}_{2.51}$ powder, dissolved more rapidly than the other tungsten oxide powders. Overall, these results suggest that fiber-containing tungsten oxides that deposit in the alveolar region of the lung would have similar biopersistence to isometric-shaped $\mathrm{WO}_{3}$ and $\mathrm{WO}_{2.98}$, but would be more biopersistent than tungsten metal.

The toxicity of tungsten compounds provides limited clues as to potential adverse effects from inhalation of tungsten oxide fibers. Workers that grind cemented tungsten carbides are exposed to mixed dusts containing tungsten, which persists in the alveoli for years [13]. Workers in the cemented tungsten carbide industry are exposed to several tungsten compounds which have a range of solubility in the body [14]. $\mathrm{WO}_{3}$ was reported 
to cause mild pulmonary fibrosis in rats [10], though this effect was not confirmed in another study [11]. Laboratory-prepared TBO materials can generate free radicals at rates higher than asbestos in vitro, which could contribute to development of pulmonary fibrosis [15] though it is unknown whether this reaction occurs in vivo. Tungsten oxide fibers can be present in workplaces that use cobalt [1] and cobalt is known to enhance the toxicity of some tungsten compounds by generating free radicals [18]. In the current study, the dissolution rates of each fiber-containing tungsten oxide powder did not differ among the as-received, dispersed, and cobalt mixture states. Hence, whether inhaled as tungsten oxide or tungsten oxide/cobalt mixtures, these powders will persist in the alveoli and present opportunity for generation of free radicals. Shvedova et al. [17] reported that dispersed SWCNT were associated with diffuse interstitial fibrosis and aggregated SWCNT induced granulomas in mouse lung. Particle dispersion may variably influence in vivo biopersistence in relation to the capacity of macrophages to engulf agglomerated versus individual fibers. In the current study, there were no differences in dissolution rates between as-received and dispersed tungsten oxide fibers. The potential for adverse health effects due to long-term persistence of tungsten oxide fibers in the alveolar region of the lung remains poorly understood.

Finally, it is interesting to note that historically, an early method for producing non-sag tungsten metal wire involved reduction of $\mathrm{WO}_{3}$. Later, in the $1970 \mathrm{~s}$, industrial producers began to use TBOs because these materials have higher surface area and therefore are better at absorbing potassium ions, which are important for product performance [2]. While the TBOs are better at absorbing potassium ions, $\mathrm{WO}_{3}$ can be made to have the same surface area as TBOs and high-quality wire can be produced using $\mathrm{WO}_{3}[3]$. The $\mathrm{WO}_{3}$ material evaluated in this study had a mean equivalent $D_{a e}$ of approximately $100 \mu \mathrm{m}$, much larger than the $\mathrm{D}_{\mathrm{ae}}$ of the three fiber-containing TBOs. Thus, when inhaled, the $\mathrm{WO}_{3}$ material evaluated in this study would be more likely to deposit in the more rapidly cleared upper conducting airways and less likely to be deposited in the more slowly cleared alveolar regions of the lung. Also, the $\mathrm{WO}_{3}$ material evaluated in this study was more soluble than the three fiber-containing TBOs evaluated in this study. In light of the measured particle physical characteristics and observed dissolution data, in vivo studies to evaluate toxicity of TBOs relative to $\mathrm{WO}_{3}$ powder may be worthwhile to determine whether substitution of $\mathrm{WO}_{3}$ for TBOs is appropriate.

\section{Summary}

The current study focused on the durability of three fibercontaining tungsten oxide powders in artificial lung fluids and compared their dissolution behavior to tungsten metal and two isometric-shaped tungsten oxide powders. Dissolution rates of tungsten compounds were one to four orders of magnitude slower in PSF compared to SUF. The physical state of the tungsten oxides (as-received versus dispersed) had no effect on dissolution behavior in either SUF or PSF. The presence of cobalt did not influence dissolution of the fiber-containing tungsten oxide powders; however, dissolution rates of $\mathrm{WO}_{3}$ and $\mathrm{WO}_{2.98}$ in SUF were slowed by cobalt. Compared to tungsten metal powder, a known mild pulmonary irritant, dissolution rates of fiber-containing $\mathrm{WO}_{2.66}$ and $\mathrm{WO}_{2.51}$ powders were slower in SUF and dissolution rates of all three fiber-containing TBO powders were slower in PSF. The slow dissolution of tungsten oxide fibers, coupled with existing toxicology information on tungsten compounds, suggests additional research is needed to fully understand the hazard potential of these fibers.

\section{Acknowledgements}

The author thanks M. Duling, R. Lawrence, D. Sbarra, and B. Tift for their assistance and M.D. Hoover and M.A. Virji for helpful discussions and critical review of this manuscript. The findings and conclusions in this report are those of the author and do not necessarily represent the views of the National Institute for Occupational Safety and Health.

This work was supported by the National Toxicology Program through interagency agreement Y1-ES-9045-15 with the National Institute for Occupational Safety and Health. The funding source had no role in the study design; data collection, analysis and interpretation; in the writing of the report; or in the decision to submit this paper for publication.

\section{Authors' contributions}

ABS designed the study, coordinated its completion, and drafted the manuscript. The author read and approved the final manuscript.

\section{Competing interests}

The authors declare that they have no competing interests.

Received: 23 September 2010 Accepted: 2 December 2010 Published: 2 December 2010

\section{References}

1. McKernan JL, Toraason MA, Fernback JE, Petersen MR: Presence of tungsten-containing fibers in tungsten refining and manufacturing processes. Ann Occup Hyg 2009, 53:215-224.

2. Lunk H-J, Ziemer B, Salmen M, Heidemann D: What is behind "tungsten blue oxides"? Refractory Metals Hard Materials 1993, 12:17-26.

3. Lassner E, Schubert W-D: Tungsten blue oxide. Int J Refractory Metals Hard Materials 1995, 13:111-117.

4. Sahle W: Possible role of tungsten oxide whiskers in hard-metal pneumoconiosis. Chest 1992, 102:1310.

5. Sahle W, Laszlo I, Krantz S, Christensson B: Airborne tungsten oxide whiskers in a hard-metal industry. Preliminary findings. Ann Occup Hyg 1994, 38:37-44.

6. Sahle W, Krantz S, Christensson B, Laszlo I: Preliminary data on hard metal workers exposure to tungsten oxide fibers. Sci Total Environ 1996, 191:153-167

7. McKernan JL, Toraason MA, Fernback JE: Presence of airborne fibers in tungsten refining and manufacturing processes: Preliminary characterization. J Occup Environ Hyg 2008, 5:463-474.

8. Davis JMG: The role of clearance and dissolution in determining the durability and biopersistance of mineral fibers. Environ Health Perspect 1994, 102(Suppl 5):113-117. 
9. Oberdörster G: Toxicokinetics and effects of fibrous and nonfibrous particles. Inhal Toxicol 2002, 14:29-56.

10. Keith LS, Moffett DB, Rosemond ZA, Wohlers DW: ATSDR evaluation of health effects of tungsten and relevance to public health. Toxicol Indust Health 2007, 23:347-387.

11. Wang FS, Liu LF, Chen NM, Li YR: A study on cellular reactions and fibrogenic effects of mineral dusts. Biomed Environ Sci 1994, 7:116-121.

12. Aamodt RL: Inhalation of $181-\mathrm{W}$ labeled tungstic oxide by six beagle dogs. Health Phys 1975, 26:733-742.

13. Rüttner JR, Spycher MA, Stolkin I: Inorganic particulates in pneumoconiotic lungs of hard metal grinders. Br J Indust Med 1987, 44:657-660.

14. Kraus T, Schramel P, Schaller KH, Zöbelein P, Weber A, Angerer J: Exposure assessment in the hard metal manufacturing industry with special regard to tungsten and its compounds. Occup Environ Med 2001, 58:631-634.

15. Leanderson $\mathrm{P}$, Sahle $\mathrm{W}$ : Formation of hydroxyl radicals and toxicity of tungsten oxide fibres. Toxicol In Vitro 1995, 9:175-183.

16. Stefaniak AB, Day GA, Harvey CJ, Leonard SS, Schwegler-Berry DE, Chipera SJ, Sahakian NM, Chisholm WP: Characteristics of dusts encountered during the production of cemented tungsten carbides. Ind Health 2007, 45:793-803.

17. Shvedova AA, Kisin ER, Mercer R, Murray AR, Johnson VJ, Potapovich Al, Tyurina YY, Gorelik O, Arepalli S, Schwegler-Berry D, Hubbs AF, Antonini J, Evans DE, Ku BK, Ramsey D, Maynard A, Kagan VE, Castranova V, Baron P: Unusual inflammatory and fibrogenic pulmonary responses to singlewalled carbon nanotubes in mice. Am J Physiol Lung Cell Mol Physiol 2005, 289:L698-L708

18. Lison D, Lauwerys $R$ : The interaction of cobalt metal with different carbides and other mineral particles on mouse peritoneal macrophages. Toxicol In Vitro 1995, 9:341-347.

19. International Organization for Standardization: ISO 14887:2000: Sample preparation - Dispersing procedures for powders in liquids ISO, Geneva, Switzerland; 2000

20. ASTM International: ASTM B922-02: Standard Test Method for Metal Powder Specific Surface Area by Physical Adsorption ASTM International, West Consohocken, PA; 2002.

21. Vaughan NP: The aerodynamic behaviour of cylindrical and spheroidal particles when settling under gravity. J Aerosol Sci 1986, 17:53-65.

22. Hinds WC: Aerosol Technology: Properties, behavior, and measurement of airborne particles New York: John Wiley and Sons; 1999.

23. ASTM International: ASTM D5291- 02: Standard Test Methods for Instrumental Determination of Carbon, Hydrogen, and Nitrogen in Petroleum Products and Lubricants ASTM International, West Conshohocken, PA; 2002.

24. ASTM International: ASTM D5373-08: Standard Test Methods for Instrumental Determination of Carbon, Hydrogen, and Nitrogen in Laboratory Samples of Coal ASTM International, West Conshohocken, PA; 2008.

25. ASTM International: ASTM D4239-08 Standard Test Methods for Sulfur in the Analysis Sample of Coal and Coke Using High-Temperature Tube Furnace Combustion Methods ASTM International West Conshohocken, PA; 2008.

26. National Institute for Occupational Safety and Health: In NIOSH Manual of Analytical Methods $\left(\mathrm{NMAM}^{ }\right)$. 4 edition. Edited by: Schlecht PC, O'Connor PF. DHHS (NIOSH) Publication 94-113 (August, 1994); 1994:, 1st Supplement Publication 96-135, 2nd Supplement Publication 98-119, 3rd Supplement 2003-154.

27. Kanapilly GM, Raabe OG, Goh CH, Chimenti RA: Measurement of in vitro dissolution of aerosol particles for comparison to in vivo dissolution in the lower respiratory tract after inhalation. Health Phys 1973, 24:497-507.

28. Finch GL, Mewhinney JA, Eidson AF, Hoover MD, Rothenberg SJ: In vitro dissolution characteristics of beryllium oxide and beryllium metal aerosols. J Aerosol Sci 1988, 19:333-342.

29. Lehnert BE, PE Morrow: Association of 59Iron oxide with alveolar macrophages during alveolar clearance. Exp Lung Res 1985, 9:1-16

30. Stefaniak AB, Guilmette RA, Day GA, Hoover MD, Breysse PN, Scripsick RC: Characterization of phagolysosomal fluid for study of beryllium aerosol particle dissolution. Toxicol In Vitro 2005, 19:123-134.

31. Bowden DH: Cell turnover in the lung. Am Rev Respir Dis 1983, 128(Suppl 2):S46-S48.

32. Occupational Safety and Health Administration: OSHA Sampling and Analytical Methods Salt Lake City, UT; 1994
33. Mercer T: On the role of particle size in dissolution of lung burdens. Health Phys 1967, 13:1211-1221.

34. Potter RM, Mattson SM: Glass fiber dissolution in a physiological saline solution. Glastech Ber 1991, 64:16-28.

35. Stefaniak AB, Virji MA, Day GA: Release of beryllium from berylliumcontaining materials in artificial skin surface film liquids. Ann Occup Hyg 2010.

36. Stefaniak AB, Harvey CJ, Bukowski VC, Leonard SS: Generation of free radicals by pre- and post-sintered cemented carbide particles. I Occup Environ Health 2010, 7:23-34.

37. International Commission on Radiological Protection: Human Respiratory Tract Model for Radiological Protection, ICRP Publication 66 1994, Exeter.

38. Collier CG, Pearce MJ, Hodgson A, Ball A: Factors affecting the in vitro dissolution of cobalt oxide. Environ Health Perspect 1992, 97:109-113.

\section{doi:10.1186/1743-8977-7-38}

Cite this article as: Stefaniak: Persistence of tungsten oxide particle/fiber mixtures in artificial human lung fluids. Particle and Fibre Toxicology 2010 7:38.

\section{Submit your next manuscript to BioMed Central and take full advantage of:}

- Convenient online submission

- Thorough peer review

- No space constraints or color figure charges

- Immediate publication on acceptance

- Inclusion in PubMed, CAS, Scopus and Google Scholar

- Research which is freely available for redistribution

Submit your manuscript at www.biomedcentral.com/submit
Ciomed Central 